\title{
Article
}

\section{The Effect of Intravenous Dexamethasone and Dexmedetomidine on Analgesia Duration of Supraclavicular Brachial Plexus Block: A Randomized, Four-Arm, Triple-Blinded, Placebo-Controlled Trial}

\author{
Boohwi Hong $1,2,3,+\left(\mathbb{D}\right.$, Chahyun Oh ${ }^{1,2,+} \mathbb{D}$, Yumin Jo ${ }^{1,2}$, Woosuk Chung ${ }^{1,2}$, Eunhye Park ${ }^{1}$, Hanmi Park ${ }^{1}$ \\ and Seokhwa Yoon 1,2,*
}

Citation: Hong, B.; Oh, C.; Jo, Y.; Chung, W.; Park, E.; Park, H.; Yoon, S. The Effect of Intravenous

Dexamethasone and

Dexmedetomidine on Analgesia Duration of Supraclavicular Brachial Plexus Block: A Randomized, Four-Arm, Triple-Blinded, PlaceboControlled Trial. J. Pers. Med. 2021, 11, 1267. https://doi.org/10.3390/ jpm11121267

Academic Editor: Hisham Fansa

Received: 23 October 2021

Accepted: 28 November 2021

Published: 1 December 2021

Publisher's Note: MDPI stays neutral with regard to jurisdictional claims in published maps and institutional affiliations.

Copyright: (c) 2021 by the authors. Licensee MDPI, Basel, Switzerland. This article is an open access article distributed under the terms and conditions of the Creative Commons Attribution (CC BY) license (https:/ / creativecommons.org/licenses/by/ $4.0 /)$.
1 Department of Anesthesiology and Pain Medicine, Chungnam National University Hospital, 282 Munhwa-ro, Jung-gu, Daejeon 35015, Korea; koho0127@gmail.com (B.H.); ohchahyun@gmail.com (C.O.); lemonny87@naver.com (Y.J.); woosuk119@gmail.com (W.C.); beareunbear@gmail.com (E.P.); invent2424@naver.com (H.P.)

2 Department of Anesthesiology and Pain Medicine, College of Medicine, Chungnam National University, 266 Munhwa-ro, Jung-gu, Daejeon 35015, Korea

3 Big Data Center, Biomedical Research Institute, Chungnam National University Hospital, 282 Munhwa-ro, Jung-gu, Daejeon 35015, Korea

* Correspondence: seohwy@cnu.ac.kr

+ Contributed equally to this work as co-first author.

Abstract: Intravenous dexamethasone and dexmedetomidine, in conjunction with peripheral nerve blockade, have each been reported to prolong the duration of analgesia. This study tested whether combined use further prolongs analgesia duration after supraclavicular brachial plexus block (BPB) in patients undergoing orthopedic upper extremity surgery. One hundred twenty patients were randomized 1:1:1:1 to Control (saline bolus and midazolam infusion [0.05 mg/ $\mathrm{kg}$ loading, $20 \mu \mathrm{gg} / \mathrm{kg} / \mathrm{h}$ thereafter]); DMED (saline bolus and dexmedetomidine infusion [1 $\mu \mathrm{g} / \mathrm{kg}$ loading, $0.4 \mu \mathrm{g} / \mathrm{kg} / \mathrm{h}$ thereafter]); DEXA (dexamethasone [10 mg] bolus and midazolam infusion); and DMED-DEXA (dexmedetomidine infusion and dexamethasone bolus) groups. The primary outcome was the duration of postoperative analgesia, defined as the time from the end of the BPB to the first dose of analgesia via a patient-controlled device. Median (interquartile range) times to first dose of analgesia in the Control, DMED, DEXA, and DMED-DEXA groups were 8.1 (6.2-11.6), 9.0 (8.1-11.3), 10.7 (8.1-20.5), and 13.2 (11.5-19.1) hours, respectively $(p<0.001)$. Pairwise comparisons showed significant prolongation of analgesia in the DEXA included groups compared with the non-DEXA included groups (DEXA vs. control, $p=0.045$; DEXA vs. DMED, $p=0.045$; DMED-DEXA vs. control, $p<0.001$; DMED-DEXA vs. DMED, $p<0.001$ ). A mixed effect model showed that dexamethasone was the only significant factor for the prolongation of analgesia $(p<0.001)$. Intravenous dexamethasone prolonged the analgesia duration of supraclavicular BPB after orthopedic upper extremity surgery. The concurrent use of mild to moderate sedation dose of intravenous dexmedetomidine in addition to intravenous dexamethasone showed no additional benefit to the prolongation of analgesia.

Keywords: dexmedetomidine; dexamethasone; intravenous adjuvant; regional anesthesia; brachial plexus block; postoperative analgesia

\section{Introduction}

Brachial plexus block (BPB) is widely used for upper extremity surgery because it provides both intraoperative anesthesia and postoperative analgesia [1,2]. However, as the duration of analgesia is limited to the day of surgery [3,4], it may cause rebound pain, which can result in sleep disturbance and/or unplanned use of health care resources [5-7].

Prolonging the effect of BPB is of interest in regional anesthesia. Continuous regional analgesia using a catheter or intravenous or intraneural adjunctive agents such 
as dexamethasone [8] and dexmedetomidine [9-11] is a frequent option. Administration of continuous regional analgesia, however, is technically cumbersome and not suitable for ambulatory anesthesia in some countries, making adjunctive agents more attractive. Intravenous adjunctive agents are free of concerns regarding "off label use" and have been shown to be as effective as perineural injection [12-16].

According to our previous study, sedation with dexmedetomidine can prolong the analgesia duration of BPB [11]. We hypothesized that the prolonged analgesic duration of BPB induced by dexmedetomidine can be augmented by concurrent administration of intravenous dexamethasone. The effects of these adjunctive agents on the analgesia duration of BPB were therefore evaluated in a four parallel-arm study, in which patients received dexamethasone, dexmedetomidine, neither or both.

\section{Materials and Methods}

This study included 120 patients aged 20-70 years with American Society of Anesthesiologists (ASA) physical status I or II, who were scheduled for elective upper extremity surgery under supraclavicular BPB. Patients were excluded if they refused to participate; had preexisting neuropathy of the surgical limb, hypersensitivity to amide anesthetic, significant pulmonary disease, coagulopathy, sepsis, infection at the block site, or pregnancy. The study protocol was approved by the Institutional Research Board of Chungnam National University Hospital, Daejeon, Republic of Korea (CNUH 2019-04-022-002), and all participants provided written informed consent. The study was registered with Clinical Research information Service (CRIS, https:/ / cris.nih.go.kr, KCT0004093, last accessed on 21 September 2021) on 26 June 2019, participants enrolled from 28 June 2019 to 26 June 2020.

Study data were collected and managed using REDCap (Research Electronic Data Capture) software hosted at Chungnam National University Hospital. REDCap is a secure, web-based platform designed to support capture of data for research studies [17]. This manuscript adheres to the applicable CONSORT (Consolidated Standards of Reporting Trials) guidelines [18].

Patients were randomized 1:1:1:1 to four groups: a Control group, a dexmedetomidine (DMED) group, a dexamethasone (DEXA) group, and a dexmedetomidine plus dexamethasone (DMED-DEXA) group. A computer-generated (www.randomization.com, accessed on 30 May 2019) randomization table with blocks of 4 and 8 was created. The sequence was uploaded into REDCap (redcap.cnuh.co.kr, accessed on 30 May 2019) to conceal the allocation, and a researcher (Y.J.) allocated each patient to the indicated group immediately after patient arrival at the operating room. After preparing the study drugs, the researcher exposed to the allocation was not involved in any part of study conduction. Other individuals who participated in the surgery, including the attending anesthesiologist, surgeon, and nurse, were blinded to the assignment.

\subsection{Preparation of Study Drugs}

Midazolam was used as a sedative agent in the control and DEXA group. Sedative agents included $30 \mathrm{~mL}$ of $4 \mu \mathrm{g} / \mathrm{mL}$ dexmedetomidine (Precedex Premix, Pfizer Pharmaceuticals Korea, Seoul, Korea) and $30 \mathrm{~mL}$ of $0.2 \mathrm{mg} / \mathrm{mL}$ midazolam, consisting of $6 \mathrm{~mL}$ midazolam (Midazolam inj, 1 mg/mL, ${ }^{\circledR}$ Bukwang Pharmaceutical Co. Ltd., Seoul, Korea) added to $24 \mathrm{~mL}$ of normal saline, with $2 \mathrm{~mL}$ of $5 \mathrm{mg} / \mathrm{mL}$ dexamethasone (dexamethasone disodium phosphate injection ${ }^{\circledR}$, Yuhan Pharm, Seoul, Korea) or normal saline included as a bolus intravenous adjunctive agent or placebo, respectively (Figure 1). All sedative agents were administered at a loading rate of $1.5 \mathrm{~mL} / \mathrm{kg} / \mathrm{h}$ for $10 \mathrm{~min}$ (i.e., $0.25 \mathrm{~mL} / \mathrm{kg}$ for $10 \mathrm{~min}$ ) and a maintenance rate of $0.1 \mathrm{~mL} / \mathrm{kg} / \mathrm{h}$ until the beginning of skin suture. These regimens translate into a $1.0 \mu \mathrm{g} / \mathrm{kg}$ loading dose and a $0.4 \mu \mathrm{g} / \mathrm{kg} / \mathrm{h}$ continuous dose for dexmedetomidine and a $0.05 \mathrm{mg} / \mathrm{kg}$ loading dose and a $20 \mu \mathrm{g} / \mathrm{kg} / \mathrm{h}$ continuous dose for midazolam. Drug dosages were based on ideal body weight. 


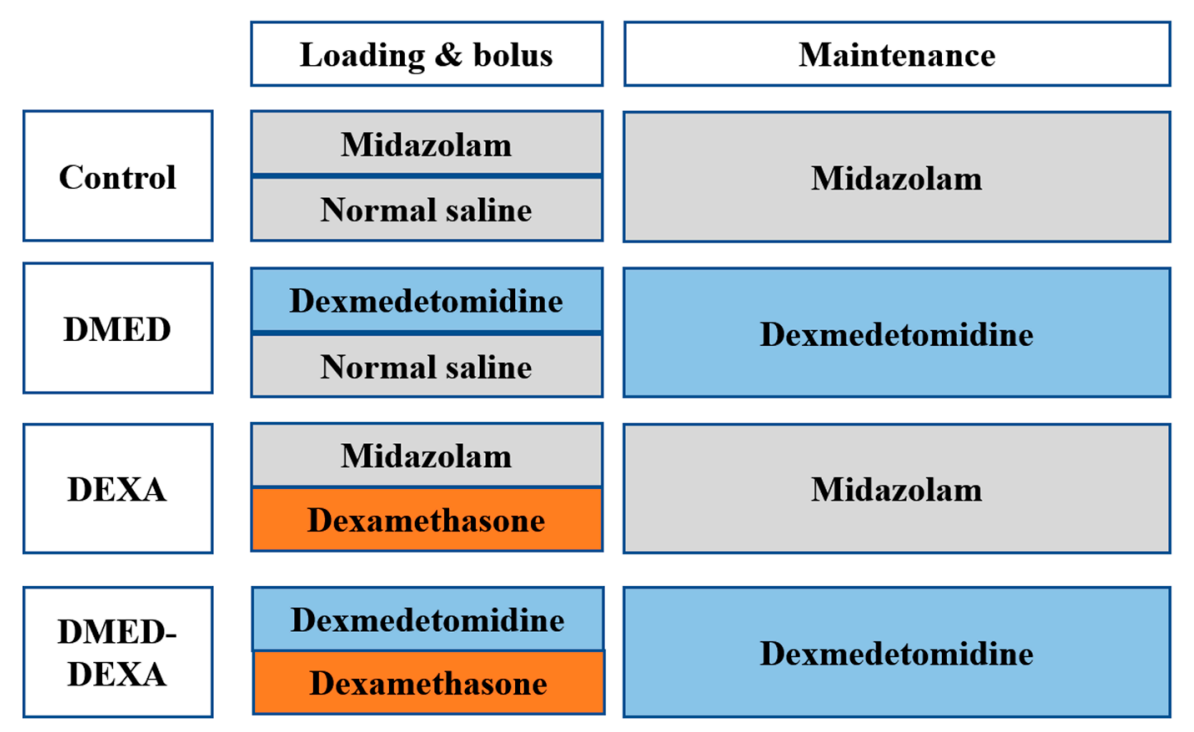

Figure 1. Schedule of drug administration to patients in the four study groups. Patients in the Control group received a $2 \mathrm{~mL}$ bolus of normal saline, followed by infusion of midazolam $(0.05 \mathrm{mg} / \mathrm{kg}$ loading dose and a $20 \mu \mathrm{g} / \mathrm{kg} / \mathrm{h}$ continuous dose). Patients in the DMED group received a $2 \mathrm{~mL}$ bolus of normal saline, followed by infusion of dexmedetomidine $(1.0 \mu \mathrm{g} / \mathrm{kg}$ loading dose and a $0.4 \mu \mathrm{g} / \mathrm{kg} / \mathrm{h}$ continuous dose). Patients in the DEXA group received a $2 \mathrm{~mL}$ bolus of dexamethasone, followed by infusion of midazolam. Patients in the DMED-DEXA group received a $2 \mathrm{~mL}$ bolus of dexamethasone, followed by infusion of dexmedetomidine.

\subsection{Anesthetic Procedures}

Standard ASA monitoring was applied before performing the block and was maintained throughout the entire procedure. All supraclavicular blocks were performed under ultrasound guidance by a single experienced anesthesiologist (B.H.) using an in-plane technique with a high-resolution ultrasound system (X-Porte, FUJIFILM SonoSite, Inc., Bothell, WA, USA), a high-frequency linear probe (HFL50xp: 15-6 MHz, X-Porte) and a nerve stimulator $(0.1 \mathrm{~ms}, 0.5 \mathrm{~mA}, 2 \mathrm{~Hz}$, sentinel mode, MultiStim SENSOR, PAJUNK, Geisingen, Germany). All patients were administered $25 \mathrm{~mL}$ of local anesthetic, consisting of a $1: 1$ mixture of $1 \%$ lidocaine and $0.75 \%$ ropivacaine. After confirmation of surgical readiness by pinprick in terminal nerve dermatomes (i.e., radial, median, ulnar, musculocutaneous) related to the operating field, the study drug was infused. A block failure was defined as the requirement for general anesthesia or additional infiltration of local anesthetics in the field due to inadequate anesthesia in the operating arm. Prior to sedation, supplemental oxygen was administered at a rate of $5 \mathrm{~L} / \mathrm{min}$ via a simple facial mask. Once oral intake was tolerated in postoperative day, all patients received oral analgesia twice a day (combination of tramadol $37.5 \mathrm{mg}$ and acetaminophen $325 \mathrm{mg}$, combination of naproxen $500 \mathrm{mg}$ and esomeprazole $20 \mathrm{mg}$ ). Patient-controlled analgesia (PCA) devices (Accumate ${ }^{\circledR} 1200$, Woo Young Meditech, Seoul, Korea) were set to administer bolus doses of fentanyl $0.5 \mu \mathrm{g} / \mathrm{kg}$ (no continuous dose, lockout time of $10 \mathrm{~min}$, total fentanyl dose of $1000 \mu \mathrm{g}$ ) and continued on discharge day. Rescue analgesic (intravenous pethidine $25 \mathrm{mg}$ ) was prescribed when the patient complaint pain greater than NRS 3 despite the use of PCA. All patients remained in the hospital for one to two days after surgery and were followed up at the outpatient clinic on 7 to 14 days after surgery.

\subsection{Outcomes}

The primary outcome was the time until the patient first required analgesia, defined as the time from the end of the injection of local anesthetic to the first bolus dose infused via a PCA device. Data regarding the use of PCA devices were collected using AccuLinker software (data extraction program of Accumate ${ }^{\circledR} 1200$ version 1.1, Woo Young Meditech, 
Seoul, Korea), which records the exact time and dose of every administration made by the device.

Secondary outcomes included: (1) duration of sensory and motor block, (2) 24-h cumulative opioid consumption, (3) pain severity (maximum [NRS], minimum [NRS], and frequency of severe pain) over $24 \mathrm{~h}$, (4) sleep quality, (5) satisfaction score, (6) pre- and postoperative blood glucose concentrations, (7) hemodynamic measurements (systolic and diastolic blood pressure, heart rate), and (8) level of sedation. Patients were instructed to assess the sensory and motor functions of their blocked arm, compared with the contralateral arm or baseline (before the blockade), every $30 \mathrm{~min}$ postoperatively. The durations of sensory and motor blockade were defined as the times from the end of injection until the patient detected complete resolution of the sensory and motor blockades (end of self-assessment), respectively. The frequency of severe pain for $24 \mathrm{~h}$ postoperatively was reported using a 10-point scale, ranging from 0 for no severe pain to 10 for the consistent perception of severe pain. Sleep quality and satisfaction scores were assessed the morning after surgery on 10-point scales by a researcher, who was blinded to the group assignment. Preoperative and postoperative blood glucose concentrations on the day of surgery after transfer to the ward were measured using standard laboratory tests. Hemodynamic changes, including systolic blood pressure and heart rate, were recorded at seven time points from the start of sedation to $30 \mathrm{~min}$ after the end of sedative infusion (i.e., 0, 5, 10, and $30 \mathrm{~min}$ after the start of sedation; and 0, 10, and $30 \mathrm{~min}$ after the end of sedative infusion). Intraoperative sedation level was evaluated using the modified Ramsay Sedation Scale (mRSS) 5 and $10 \mathrm{~min}$ after the start of sedation and every $10 \mathrm{~min}$ thereafter through $50 \mathrm{~min}$. After surgery, all patients transferred post anesthesia care unit and Modified Aldrete post-anesthesia score was adopted as the discharge criteria, which a score $>9$ is needed for discharge. Patients who fulfilled the discharge criteria were transferred to the ward unit.

\subsection{Statistical Analysis}

Sample size was estimated based on our previous study, which evaluated the analgesic duration of BPB after sedation using dexmedetomidine [11]. That study showed that the mean \pm standard deviation (SD) duration of analgesia in the dexmedetomidine group was $616.9 \pm 158.2 \mathrm{~min}$. Based on a 30\% increase in duration of analgesia being clinically significant, and assuming a power of 0.9 and a two-sided alpha of $0.0083(0.05 / 6)$ for multiple comparisons of post hoc analysis when the difference in variance of four groups is significant, then the minimum sample size would be 25 patients. Potential patient dropout and data loss indicated that the minimum sample size was 120 patients ( 30 patients per group).

Depending on the results of Shapiro-Wilk tests, continuous variables were reported as mean $\pm \mathrm{SD}$ and compared by independent $t$-tests or as median (interquartile range [IQR]) and compared by Kruskal-Wallis tests. Categorical variables were reported as number (\%) and compared by using $\chi^{2}$ or Fisher's exact tests. Time-to-event outcomes such as duration of analgesia (primary outcome) and sensory and motor blockade were determined by Kaplan-Meier survival analysis and compared by log-rank tests, with pairwise comparisons with $p$-value adjustment performed using the Benjamini and Hochberg method. The effects of each two drugs and the interaction term between them were tested using mixed-effect models for the analgesic duration and the repeated measurements (e.g., systolic blood pressure, heart rate, sedation score). A two-tailed $p$-value $<0.05$ was considered statistically significant. Only the complete cases (without missing data for the primary outcome) were involved in the entire analysis. All analyses were performed using R software version 4.0.3 (R Project for Statistical Computing, Vienna, Austria). 


\section{Results}

\subsection{Study Participants}

Total 126 patients were assessed for eligibility. Six patients refused to participate and were thus excluded, whereas the remaining 120 patients were randomly assigned to one of the four groups (30 patients per group). Primary outcomes could not be assessed in nine patients, due to the loss of log records from the PCA device. The CONSORT flow diagram is shown in Figure 2. The baseline characteristics of the participants are shown in Table 1. None of the patients experienced BPB failure.

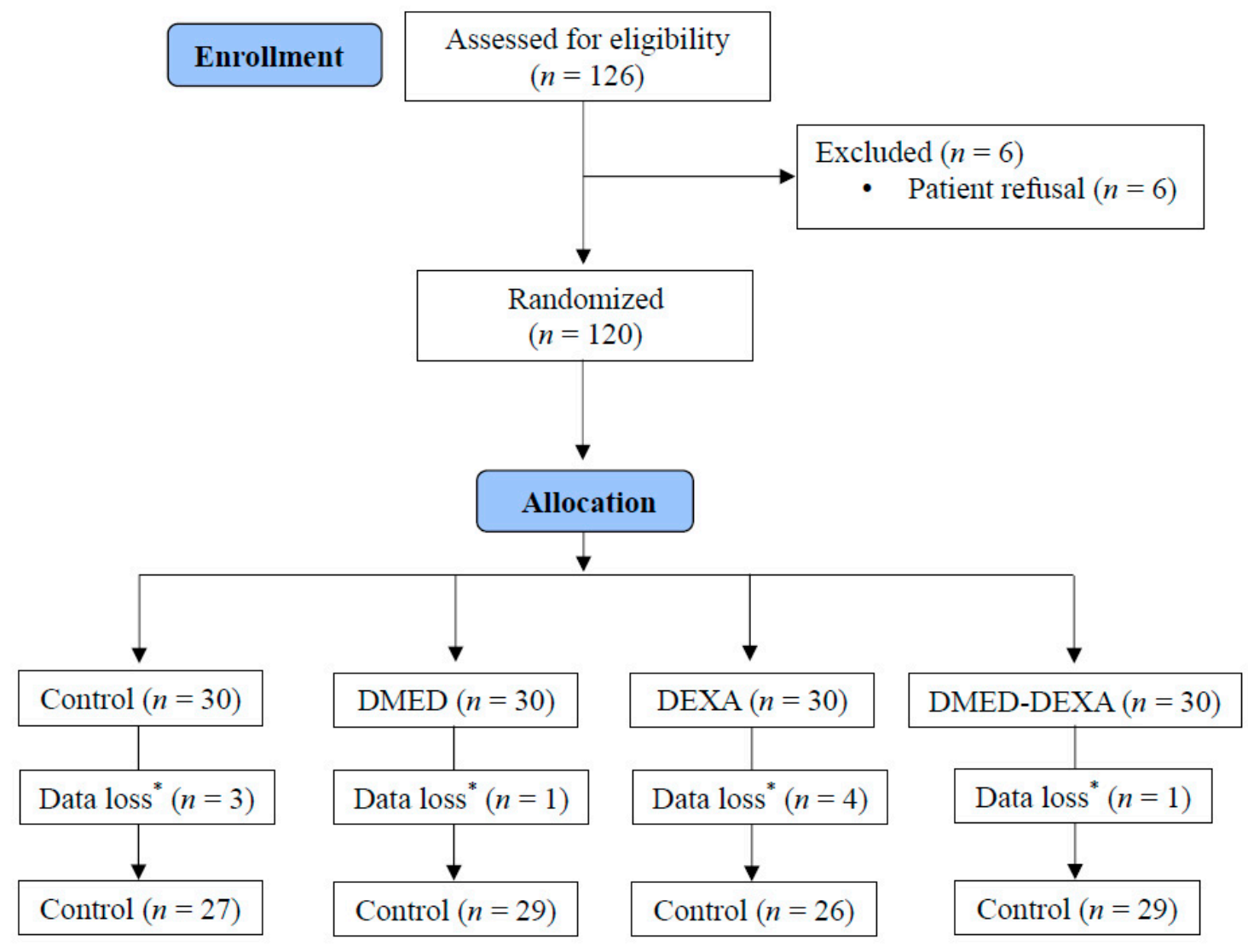

Figure 2. CONSORT flow diagram. * Data loss regarding the primary outcome (patient-controlled analgesia data).

Table 1. Demographic and clinical characteristics of the study groups. Results are reported as median [interquartile range $(\mathrm{IQR})]$ or as number $(\%) .{ }^{*}$ Duration of standard ASA monitoring during stay in the operating room.

\begin{tabular}{|c|c|c|c|c|}
\hline & $\begin{array}{l}\text { Control } \\
(n=30)\end{array}$ & $\begin{array}{l}\text { DMED } \\
(n=30)\end{array}$ & $\begin{array}{c}\text { DEXA } \\
(n=30)\end{array}$ & $\begin{array}{l}\text { DMED-DEXA } \\
\quad(n=30)\end{array}$ \\
\hline Age (y) & $57.5[48.0-66.0]$ & $57.5[34.0-65.0]$ & $55.5[31.0-64.0]$ & $55.5[41.0-59.0]$ \\
\hline Female, $n(\%)$ & $13(43.3 \%)$ & $12(40.0 \%)$ & $15(50.0 \%)$ & $11(36.7 \%)$ \\
\hline Height $(\mathrm{cm})$ & 161.6 [154.0-170.0] & 157.9 [150.0-171.6] & 161.1 [156.0-170.0] & 160.2 [154.9-166.5] \\
\hline Weight (kg) & $61.5[56.4-68.0]$ & $62.5[54.7-71.0]$ & $63.1[55.8-76.0]$ & $63.0[53.7-69.0]$ \\
\hline $\begin{array}{l}\text { Preoperative blood glucose } \\
(\mathrm{mg} / \mathrm{dL})\end{array}$ & $109.0[96.0-119.0]$ & $108.5[97.0-117.0]$ & $113.0[100.0-128.0]$ & $110.5[96.0-133.0]$ \\
\hline Monitoring time * $(\min )$ & 81.0 [73.0-97.0] & 99.0 [77.0-122.0] & 81.0 [74.0-104.0] & 91.5 [76.0-105.0] \\
\hline Dexmedetomidine $(\mu \mathrm{g})$ & & $75.6[64.0-90.4]$ & & $67.8[61.2-83.6]$ \\
\hline Dexmedetomidine $(\mu \mathrm{g} / \mathrm{kg})$ & & $1.2 \pm 0.3$ & & $1.1 \pm 0.3$ \\
\hline Midazolam (mg) & $3.7[3.1-4.3]$ & & $4.0[3.5-4.7]$ & \\
\hline \multicolumn{5}{|l|}{ Diagnosis, $n(\%)$} \\
\hline Fracture & $27(90.0 \%)$ & $21(70.0 \%)$ & $21(70.0 \%)$ & $20(66.7 \%)$ \\
\hline Ulna impaction syndrome & $3(10.0 \%)$ & $9(30.0 \%)$ & $9(30.0 \%)$ & $10(33.3 \%)$ \\
\hline
\end{tabular}




\subsection{Outcomes}

Median (IQR) times to first request for analgesia differed significantly among the Control (8.1 [6.2 to 11.6] hours), DMED (9.0 [8.1 to 11.3] hours); DEXA (10.7 [8.1 to 20.5] hours), and DMED-DEXA (13.2 [11.5 to 19.1] hours) groups ( $p<0.001)$ (Figure 3). Pairwise comparisons showed significant prolongation of analgesia in the DEXA included groups compared with the non-DEXA included groups (DEXA vs. control, $p=0.045$; DEXA vs. DMED, $p=0.045$; DMED-DEXA vs. control, $p<0.001$; DMED-DEXA vs. DMED, $p<0.001$ ) (Table A1 in Appendix A). A mixed-effect model showed that dexamethasone was the only significant factor associated with the duration of analgesia $(p<0.001)$ and the interaction between dexamethasone and dexmedetomidine was not significant $(p=0.274)$ (Table A2).

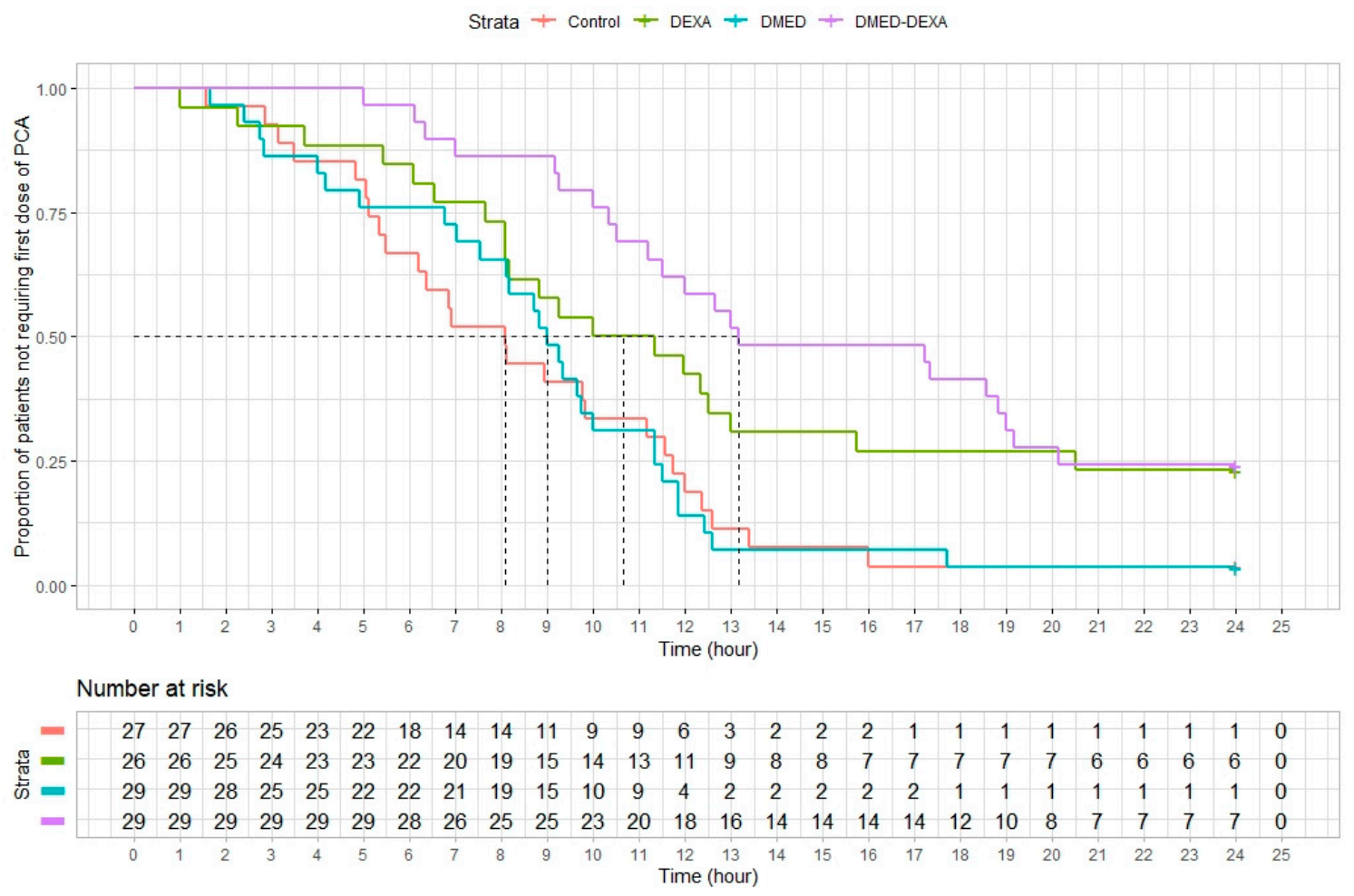

Figure 3. Survival analysis of the duration of analgesia. PCA, patient-controlled analgesia. The crossing points of the dotted and colored solid lines indicate median duration of the corresponding strata (groups). Median (IQR) times to first request for analgesia differed significantly among the Control (8.1 [6.2 to 11.6] hours), DMED (9.0 [8.1 to 11.3] hours); DEXA (10.7 [8.1 to 20.5] hours), and DMED-DEXA (13.2 [11.5 to 19.1] hours) groups $(p<0.001)$.

There were no differences in sensory and motor block duration (Figures A1 and A2). Postoperative opioid consumption and pain severity were significantly reduced, whereas sleep quality and patient satisfaction scores were significantly higher, in the DEXA and DMED-DEXA groups than in the other two groups (Table 2). Postoperative glucose was higher in the DEXA, DMED-DEXA groups, but the change (before and after surgery) was not statistically significant.

Repeated measurements, including hemodynamic variables and sedation scores, are summarized in Table A3 in Appendix A. The changes in mRSS over time did not differ significantly between the groups $(p=0.2$ ) (Figure 4 ). Hemodynamic changes during and after surgery are depicted in Figures A3 and A4. Systolic blood pressure decreased over time $(p<0.001)$, and the degree of decrease over time was significantly different between the groups (interaction between group and time, $p<0.001$ ). Systolic blood pressure continued to decrease after drug discontinuation in the DMED and DMED-DEXA groups, but did not further decrease in the Control and DEXA groups. Heart rate also showed similar results with systolic blood pressure (time and interaction between group and time, $p=0.003$ and $<0.001$, respectively). 
Table 2. Secondary outcomes. Data are presented as median [IQR], mean \pm SD or number (\%). * Pain during the first $24 \mathrm{~h}$ postoperatively rated on a 10-point scale, from 0 for no severe pain to 10 for consistent perception of severe. NRS, numeric rating scale; PONV, post-operative nausea and vomiting.

\begin{tabular}{|c|c|c|c|c|c|}
\hline & Control & DMED & DEXA & DMED-DEXA & \multirow{2}{*}{$p$} \\
\hline & $(n=27)$ & $(n=29)$ & $(n=26)$ & $(n=29)$ & \\
\hline - 24 h opioid consumption $(\mu \mathrm{g})$ & $225.0[89.0-300.0]$ & $250.0[100.0-345.0]$ & $150.0[20.0-240.0]$ & $127.5[40.0-200.0]$ & 0.044 \\
\hline - Minimal pain score (NRS) & $3.0[1.5-4.0]$ & $3.0[1.0-6.0]$ & $1.5[1.0-3.0]$ & $1.5[1.0-3.5]$ & 0.104 \\
\hline - Maximal pain score (NRS) & $7.2 \pm 3.1$ & $7.5 \pm 2.4$ & $5.1 \pm 2.7$ & $5.3 \pm 3.2$ & 0.004 \\
\hline - Frequency of the severe pain * & $5.5 \pm 2.7$ & $6.0 \pm 2.8$ & $4.2 \pm 2.9$ & $4.2 \pm 3.0$ & 0.052 \\
\hline - Sleep quality & $5.0[1.0-10.0]$ & $4.0[0.0-7.0]$ & $5.5[3.0-10.0]$ & $8.0[5.5-10.0]$ & 0.045 \\
\hline - Patient satisfaction & $7.0[5.0-10.0]$ & $8.0[5.0-10.0]$ & $8.0[6.0-10.0]$ & $10.0[7.5-10.0]$ & 0.169 \\
\hline - Postoperative glucose (mg/dL) & $109.0[92.0-121.0]$ & $105.0[91.0-132.0]$ & $113.0[105.0-172.0]$ & $117.0[110.0-133.0]$ & 0.032 \\
\hline - Glucose change (mg/dL) & $-2.0[-12.0-12.5]$ & $-3.0[-17.0-20.0]$ & $11.5[-9.0-47.0]$ & $7.0[-17.0-30.0]$ & 0.547 \\
\hline - Use of rescue analgesics, $n(\%)$ & $4(14.8 \%)$ & $5(17.2 \%)$ & $1(3.8 \%)$ & $1(3.4 \%)$ & 0.179 \\
\hline - PONV, $n(\%)$ & $9(33.3 \%)$ & $13(44.8 \%)$ & $7(26.9 \%)$ & $10(34.5 \%)$ & 0.571 \\
\hline
\end{tabular}

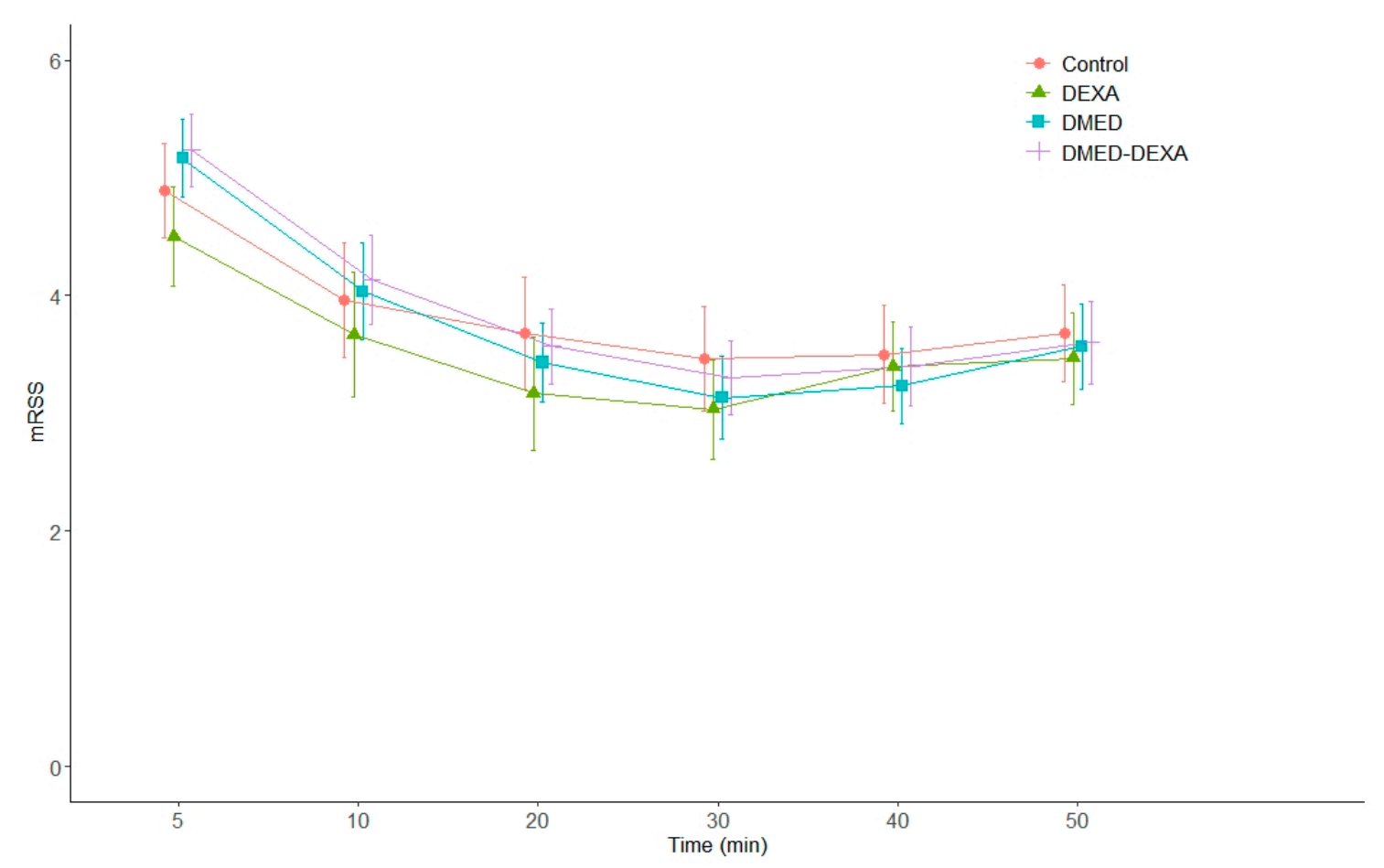

Figure 4. Changes in depth of sedation during and after surgery in the four study groups. mRSS (modified Ramsay Sedation Scale) 5 and $10 \mathrm{~min}$ after the start of sedation and every $10 \mathrm{~min}$ thereafter, up to $50 \mathrm{~min}$.

\section{Discussion}

The results of the current study suggest that intravenous dexamethasone can prolong analgesia. While the longest median analgesia duration was with patients receiving intravenous dexamethasone and dexmedetomidine sedation, the results of pairwise comparisons between the study groups and the results of the mixed effect model revealed that the prolonged duration of analgesia was actually due to the use of dexamethasone itself, and that no additional benefit could be attributed to the concurrent use of dexmedetomidine for sedation. In other words, the presence of dexmedetomidine did not alter the effect of dexamethasone on the analgesic duration of the blockade (i.e., no significant interaction between dexmedetomidine and dexamethasone).

In our previous study, dexmedetomidine sedation (mean dose of $1.6 \mu \mathrm{g} / \mathrm{kg}$ ) was found to significantly prolong the analgesic duration of the blockade about $3 \mathrm{~h} \mathrm{[11].} \mathrm{A}$ study comparing three doses of intravenous dexmedetomidine $(0.5,1.0$, and $2.0 \mu \mathrm{g} / \mathrm{kg})$ found that the duration of analgesia was prolonged significantly only in patients receiving 
$2.0 \mu \mathrm{g} / \mathrm{kg}$ of dexmedetomidine, not in those receiving 0.5 and $1.0 \mu \mathrm{g} / \mathrm{kg}$ [19]. In this context, the non-significant effect of dexmedetomidine noted in the current study could be explained by the doses used in DMED and DMED-DEXA groups (mean 1.2 and $1.1 \mu \mathrm{g} / \mathrm{kg}$, respectively). This inference is also in line with other studies which used less than $1 \mu \mathrm{g} / \mathrm{kg}$ of dexmedetomidine [20,21].

A recent randomized trial evaluating the effects of intravenous adjuncts on the analgesic duration of interscalene block in patients undergoing arthroscopic shoulder surgery reported results similar to ours [22]. That study also found that analgesic duration in patients receiving both dexmedetomidine and dexamethasone was no longer than that in patients receiving dexamethasone alone. Although the result was similar to the current study, the effect of the dexamethasone or dexmedetomidine itself could not be revealed within the study, as they omitted control group.

In contrast to our findings, a previous study showed that co-administration of intravenous dexamethasone and dexmedetomidine markedly prolonged the duration of analgesia for interscalene $\mathrm{BPB}$, compared with dexamethasone alone, in patients undergoing arthroscopic shoulder surgery [23]. Unfortunately, these studies cannot be directly compared, primarily because of differences in the type of surgery. In addition, there were differences in primary outcomes. The primary outcome of the current study was the time required for the first bolus dose of opioid via a PCA device, whereas it was the time required for the first rescue analgesics in the presence of basal infusion of opioid via a PCA device in the previous study. In addition, patients in the previous study basally infused opioid via a PCA device, resulting in no need for rescue analgesics in $23 \%$ of patients in the dexamethasone group and $50 \%$ of patients receiving dexamethasone and dexmedetomidine. Although the more practical primary outcome remains unclear, we believe that the outcome used in the current study is more sensitive for comparisons of analgesic duration.

The other outcomes are also important. First, the longer analgesic effect in the DMEDDEXA than in the other groups may be associated with lower pain scores and opioid consumption and better sleep quality in this group. The median duration of analgesia in this group $(13.17 \mathrm{~h})$, however, suggests that a considerable proportion of the patients experience pain during postoperative sleep. Strategies are therefore needed to prevent rebound pain after regional anesthesia [4]. Second, there were no significant differences in motor blockade among the four groups. In contrast, previous studies reported that intravenous administration of dexamethasone prolonged motor blockade [24,25], whereas intravenous dexmedetomidine did not $[13,19,25]$. Recently published network meta-analysis reports prolongation of sensory and motor blocks, especially with dexamethasone [25]. Such difference may be attributed to the distinct analgesic protocol, difference in the block technique and the accompanying baseline quality of the blockade. Also, self-reported outcome, the duration of motor and sensory blockade, may differ from clinical assessments by physicians. Third, high dose of dexamethasone used in the current study was based on a previous study which showed increased analgesic duration of single-shot ISB with ropivacaine with IV dexamethasone [26]. In recent published meta-analysis, only $10 \mathrm{mg}$ of IV dexamethasone significantly prolonged analgesic duration of peripheral nerve blocks not 4 and $8 \mathrm{mg}$ [27]. The same results were also shown in the recently published RCT according to dexamethasone dose in the sciatic nerve block [28]. High dose of dexamethasone may cause hyperglycemia, but the increase of blood glucose level was not significant in this study. Thus, its use should not be discouraged simply because of the concern for hyperglycemia unless the glucose level was poorly controlled preoperatively.

The present study had several limitations. First, midazolam was used for sedation in both the Control and DEXA groups. Its use was inevitable for blinding purposes, as systemic midazolam can induce reliable sedation without additional analgesic effects. Patients, however, were likely unable to discern the sedative agent, therefore not affecting the primary study outcome. Also, the use of midazolam might have affected the incidence of PONV as it has an antiemetic effect. Second, the dose of dexmedetomidine may not 
have been sufficient to prolong the analgesic effect of the blockade. However, the dosage used in the current study may be closer to the typical dose administered for sedation during regional anesthesia and may therefore cause fewer dose-related adverse effects. Although the duration of analgesia may correlate with the doses of dexmedetomidine, high doses of the latter may be associated with unintended side effects, including bradycardia, hypotension, excessive sedation, and prolonged recovery [11].

\section{Conclusions}

In conclusion, intravenous dexamethasone prolonged the analgesia duration of supraclavicular BPB after orthopedic upper extremity surgery. The concurrent use of mild to moderate sedation dose of intravenous dexmedetomidine in addition to intravenous dexamethasone showed no additional benefit to the prolongation of analgesia.

Author Contributions: Conceptualization, B.H., C.O. and S.Y.; methodology, B.H. and Y.J.; formal analysis, C.O. and B.H.; investigation, Y.J. and W.C.; resources, Y.J. and E.P.; data curation, H.P.; writing-original draft preparation, B.H., C.O. and W.C.; writing-review and editing, W.C. and S.Y.; visualization, C.O.; supervision, S.Y.; project administration, B.H. and E.P.; funding acquisition, S.Y. All authors have read and agreed to the published version of the manuscript.

Funding: This work was supported by research fund of Chungnam National University (2019-0528-01).

Institutional Review Board Statement: The study was conducted according to the guidelines of the Declaration of Helsinki, and approved by the Institutional Review Board of Chungnam National University Hospital (CNUH 2019-04-022-002, 30 May 2019).

Informed Consent Statement: Informed consent was obtained from all subjects involved in the study.

Data Availability Statement: The data presented in this study are available on request from the corresponding author.

Conflicts of Interest: The authors declare no conflict of interest.

\section{Appendix A}

Table A1. Survival analysis for the duration of analgesia and sensory and motor blockade. * Adjusted using the Benjamini and Hochberg method. Events were patients requiring analgesia and reporting sensory and motor recovery in each outcome.

\begin{tabular}{|c|c|c|c|c|c|c|c|c|}
\hline & & \multirow{2}{*}{$\begin{array}{c}\begin{array}{c}\text { Sample } \\
\text { Size }\end{array} \\
(n)\end{array}$} & \multirow{2}{*}{$\begin{array}{c}\text { Events } \\
(n)\end{array}$} & \multirow{2}{*}{$\begin{array}{c}\text { Median } \\
\text { (h) }\end{array}$} & \multirow{2}{*}{$\begin{array}{c}95 \% \text { CI } \\
\text { (h) }\end{array}$} & \multicolumn{3}{|c|}{ Pairwise Comparison $\left(p^{*}\right)$} \\
\hline & & & & & & Control & DMED & DEXA \\
\hline Analgesia & Control & 27 & 26 & 8.08 & 6.2 to 11.6 & & & \\
\hline \multirow[t]{3}{*}{ Overall $p<0.001$} & DMED & 29 & 28 & 9 & 8.12 to 11.3 & 0.955 & & \\
\hline & DEXA & 26 & 20 & 10.67 & 8.08 to 20.5 & 0.045 & 0.045 & \\
\hline & DMED-DEXA & 29 & 22 & 13.17 & 11.5 to 19.1 & $<0.001$ & $<0.001$ & 0.41 \\
\hline Sensory blockade & Control & 22 & 22 & 8.96 & 8.0 to 10.5 & & & \\
\hline \multirow[t]{3}{*}{ Overall $p=0.43$} & DMED & 25 & 25 & 8.75 & 7.0 to 11.2 & & & \\
\hline & DEXA & 26 & 26 & 10.25 & 10.0 to 13.0 & & & \\
\hline & DMED-DEXA & 25 & 25 & 10.42 & 7.75 to 14.2 & & & \\
\hline Motor blockade & Control & 22 & 22 & 9.21 & 8.08 to 10.5 & & & \\
\hline \multirow[t]{3}{*}{ Overall $p=0.89$} & DMED & 25 & 25 & 9.33 & 8.5 to 12.6 & & & \\
\hline & DEXA & 26 & 26 & 9.96 & 8.5 to 11.3 & & & \\
\hline & DMED-DEXA & 25 & 25 & 10.0 & 7.3 to 11.0 & & & \\
\hline
\end{tabular}

Table A2. The result of mixed-effect model for analgesic duration. DEXA: dexamethasone, DMED: Dexmedetomidine. * Asterisk indicates interaction between the two factors (DEXA and DMED). DEXA and DMED were treated as a factor in this model.

\begin{tabular}{cc}
\hline Variables & $p$ Value \\
\hline DEXA & $<0.001$ \\
DMED & 0.170 \\
DEXA * DMED & 0.274 \\
\hline
\end{tabular}




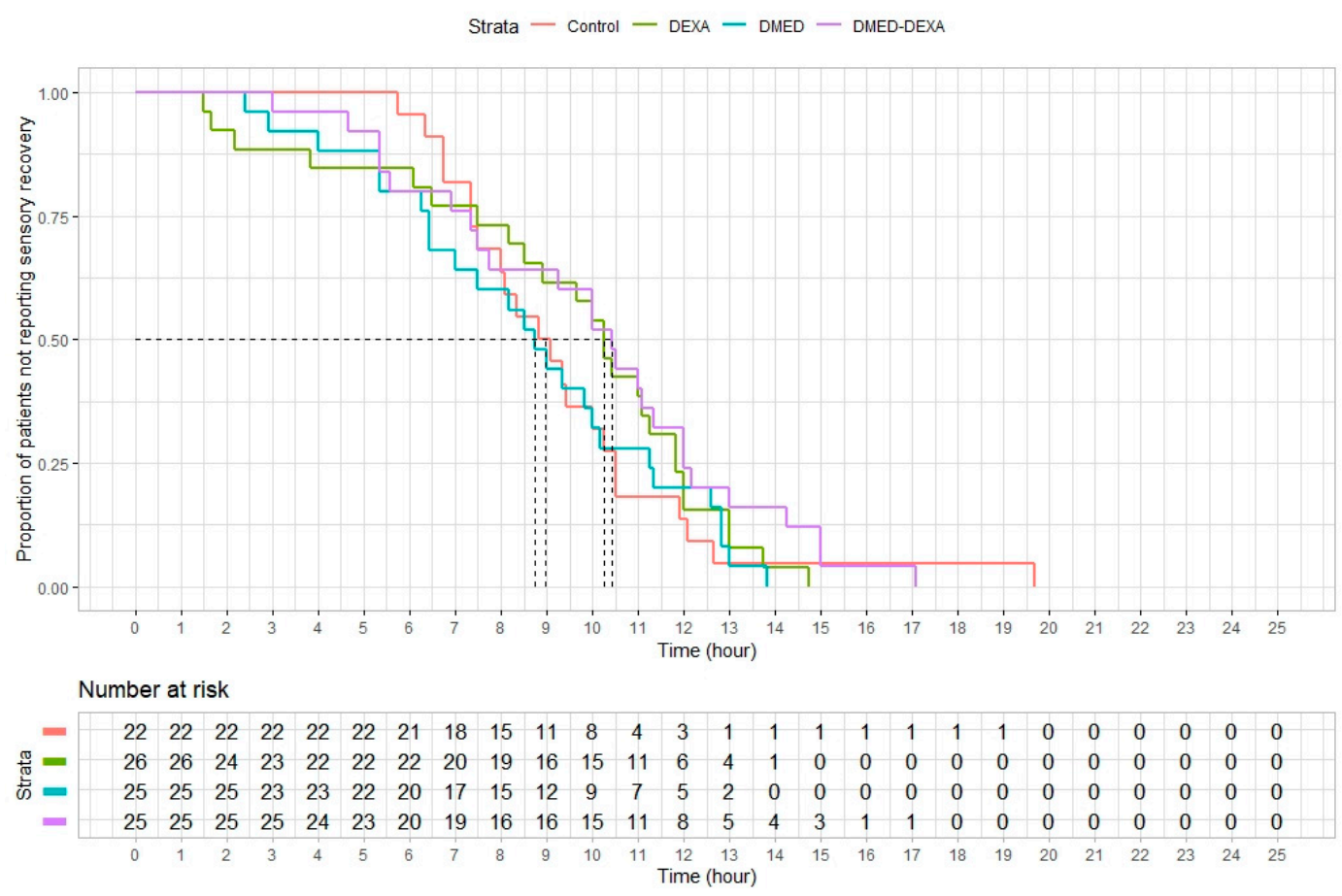

Figure A1. Survival analysis of the duration of sensory blockade. The crossing points of the dotted and colored solid lines indicate median duration of the corresponding strata (groups). There was no difference in sensory block duration $(p=0.430)$.
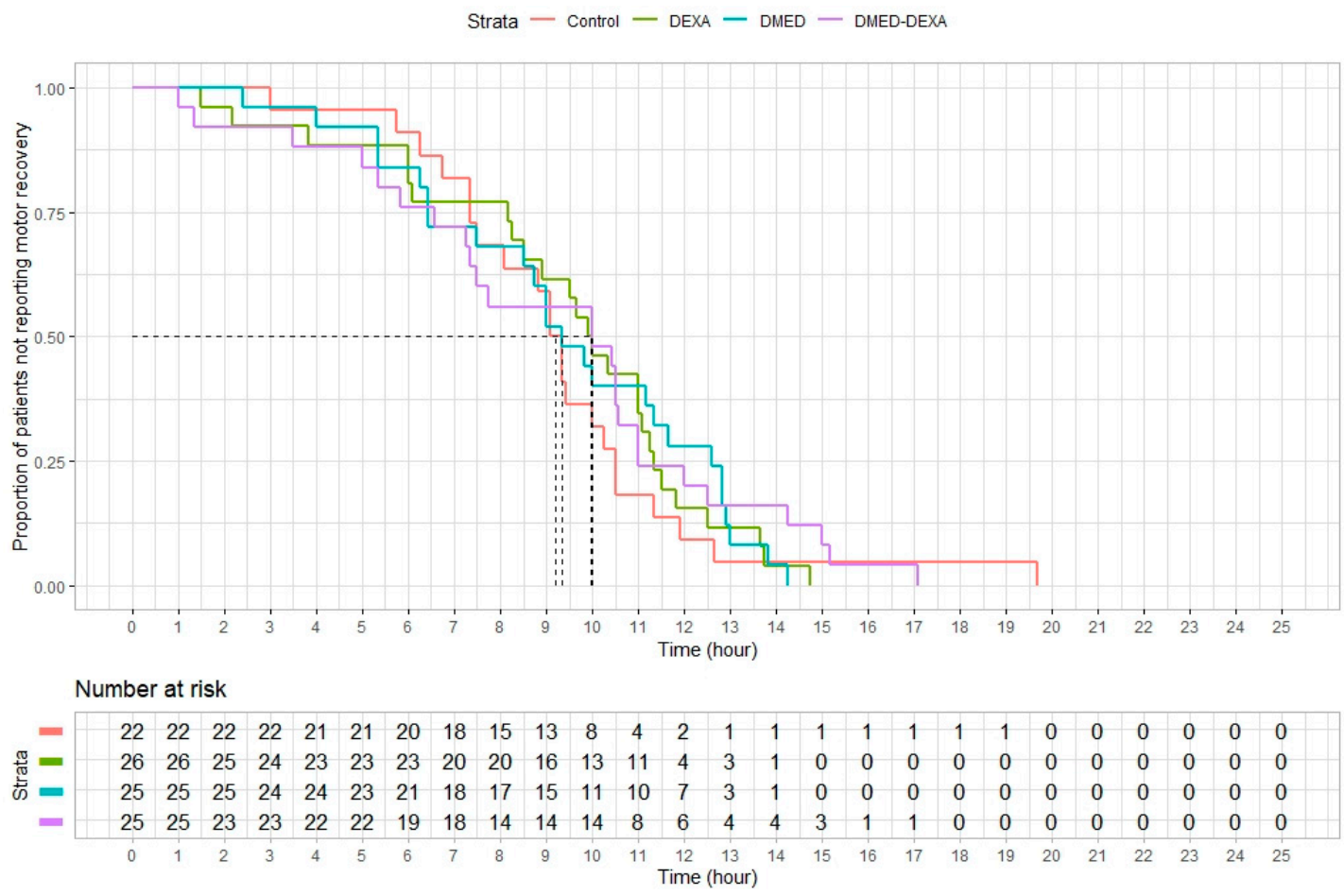

Figure A2. Survival analysis of the duration of motor blockade. The crossing points of the dotted and colored solid lines indicate median duration of the corresponding strata (groups). There was no difference in motor block duration $(p=0.895)$. 


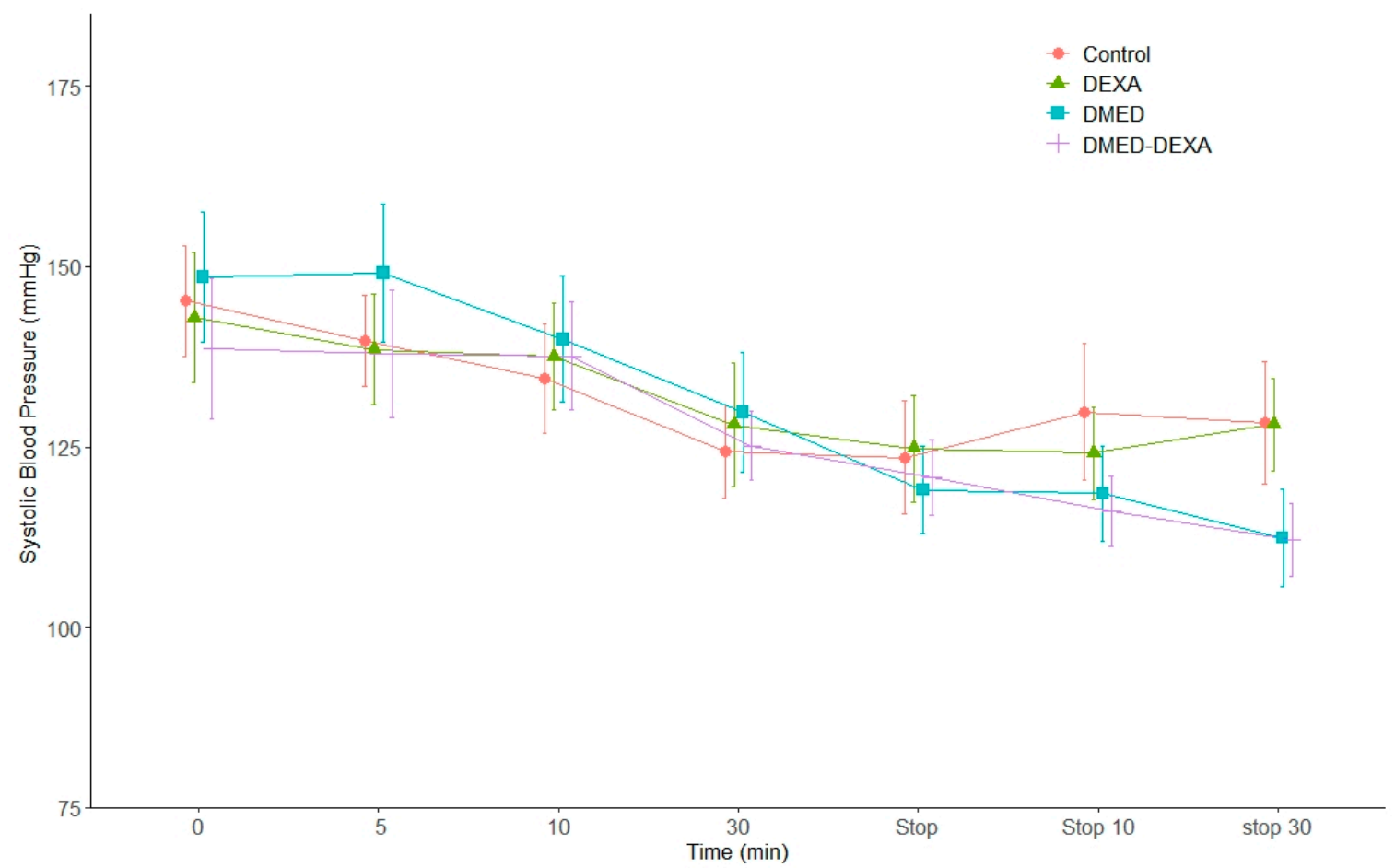

Figure A3. Changes in systolic blood pressure during and after surgery in the four study groups. The systolic blood pressure recorded at $0,5,10$, and $30 \mathrm{~min}$ after the start of sedation and 0,10 , and $30 \mathrm{~min}$ after the end of sedative infusion.

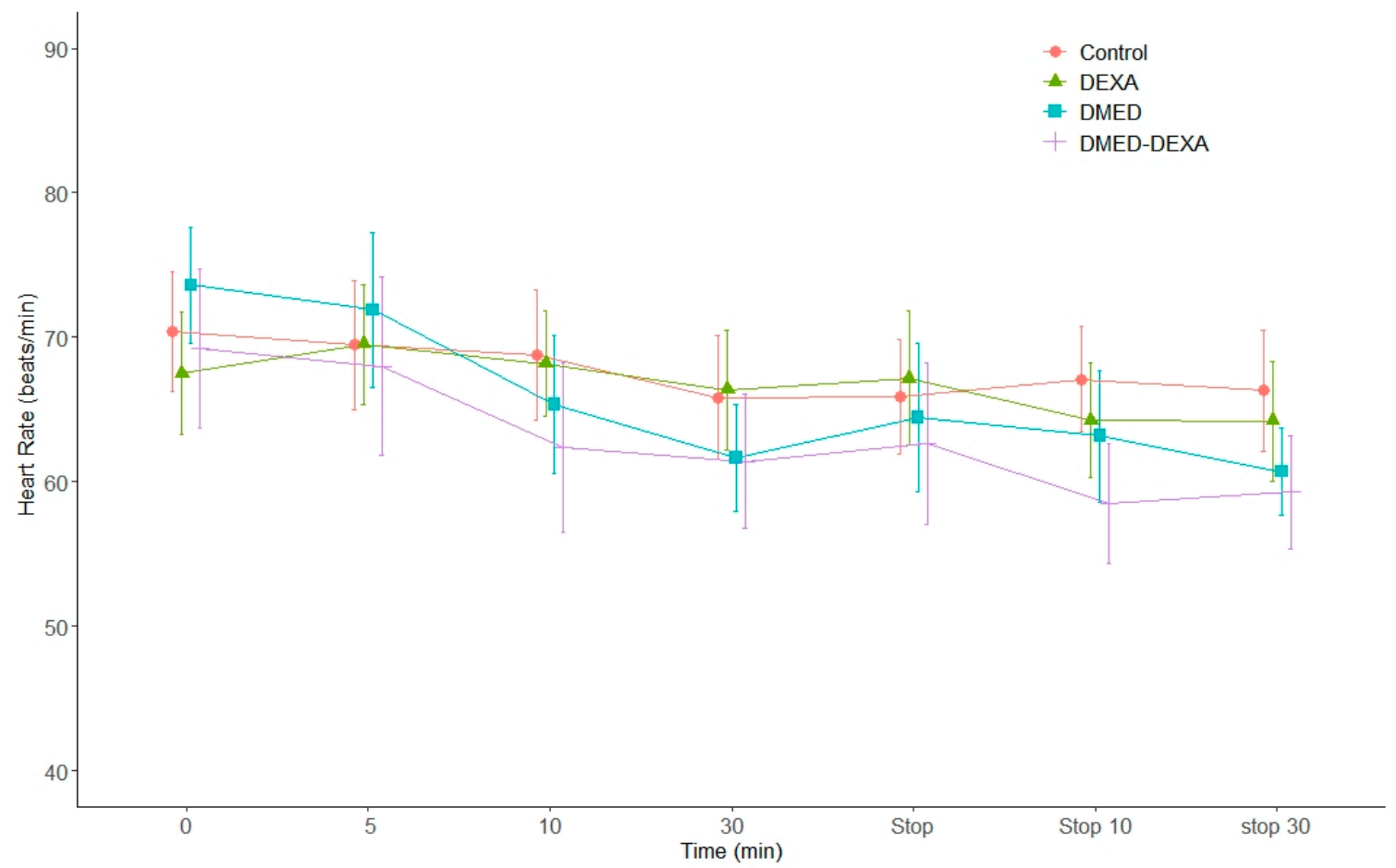

Figure A4. Changes in heart rate during and after surgery in the four study groups. The heart rate recorded at $0,5,10$, and $30 \mathrm{~min}$ after the start of sedation and 0,10 , and $30 \mathrm{~min}$ after the end of sedative infusion. 
Table A3. The results of mixed-effect models for the repeatedly measured outcomes. mRSS: modified Ramsay Sedation Scale, SBP: systolic blood pressure, HR: heart rate. * Asterisk indicates interaction between the two factors (group and time).

\begin{tabular}{cccc}
\hline & & \multicolumn{2}{c}{$p$ Value } \\
\hline Variables & mRSS & SBP & HR \\
\hline Group & 0.355 & 0.562 & 0.307 \\
Time & $<0.001$ & $<0.001$ & $<0.001$ \\
Group * Time & 0.200 & $<0.001$ & 0.003 \\
\hline
\end{tabular}

\section{References}

1. Kolny, M.; Stasiowski, M.J.; Zuber, M.; Marciniak, R.; Chabierska, E.; Pluta, A.; Jalowiecki, P.; Byrczek, T. Randomized, comparative study of the effectiveness of three different techniques of interscalene brachial plexus block using $0.5 \%$ ropivacaine for shoulder arthroscopy. Anaesthesiol. Intensive. Ther. 2017, 49, 47-52. [CrossRef]

2. Stasiowski, M.J.; Kolny, M.; Zuber, M.; Marciniak, R.; Chabierska, E.; Jalowiecki, P.; Pluta, A.; Mozdzynski, B. Randomised controlled trial of analgesic effectiveness of three different techniques of single-shot interscalene brachial plexus block using $20 \mathrm{~mL}$ of $0.5 \%$ ropivacaine for shoulder arthroscopy. Anaesthesiol. Intensive. Ther. 2017, 49, 215-221. [CrossRef]

3. Abdallah, F.W.; Halpern, S.H.; Aoyama, K.; Brull, R. Will the Real Benefits of Single-Shot Interscalene Block Please Stand Up? A Systematic Review and Meta-Analysis. Anesth. Analg. 2015, 120, 1114-1129. [CrossRef] [PubMed]

4. Brattwall, M.; Jildenstal, P.; Warren Stomberg, M.; Jakobsson, J.G. Upper extremity nerve block: How can benefit, duration, and safety be improved? An update. F1000Research 2016, 5, 907. [CrossRef] [PubMed]

5. Dada, O.; Gonzalez Zacarias, A.; Ongaigui, C.; Echeverria-Villalobos, M.; Kushelev, M.; Bergese, S.D.; Moran, K. Does Rebound Pain after Peripheral Nerve Block for Orthopedic Surgery Impact Postoperative Analgesia and Opioid Consumption? A Narrative Review. Int. J. Environ. Res. Public Health 2019, 16, 3257. [CrossRef] [PubMed]

6. Munoz-Leyva, F.; Cubillos, J.; Chin, K.J. Managing rebound pain after regional anesthesia. Korean J. Anesthesiol. 2020, 73, 372-383. [CrossRef]

7. Sunderland, S.; Yarnold, C.H.; Head, S.J.; Osborn, J.A.; Purssell, A.; Peel, J.K.; Schwarz, S.K. Regional Versus General Anesthesia and the Incidence of Unplanned Health Care Resource Utilization for Postoperative Pain After Wrist Fracture Surgery: Results From a Retrospective Quality Improvement Project. Reg. Anesth. Pain Med. 2016, 41, 22-27. [CrossRef] [PubMed]

8. Pehora, C.; Pearson, A.M.E.; Kaushal, A.; Crawford, M.W.; Johnston, B. Dexamethasone as an adjuvant to peripheral nerve block. Cochrane Database Syst. Rev. 2017, 11, CD011770. [CrossRef]

9. Vorobeichik, L.; Brull, R.; Abdallah, F.W. Evidence basis for using perineural dexmedetomidine to enhance the quality of brachial plexus nerve blocks: A systematic review and meta-analysis of randomized controlled trials. Br. J. Anaesth. 2017, 118, 167-181. [CrossRef]

10. Hussain, N.; Grzywacz, V.P.; Ferreri, C.A.; Atrey, A.; Banfield, L.; Shaparin, N.; Vydyanathan, A. Investigating the Efficacy of Dexmedetomidine as an Adjuvant to Local Anesthesia in Brachial Plexus Block: A Systematic Review and Meta-Analysis of 18 Randomized Controlled Trials. Reg. Anesth. Pain Med. 2017, 42, 184-196. [CrossRef]

11. Hong, B.; Jung, C.; Jo, Y.; Kang, H.; Chung, W.; Kim, Y.H.; Lim, C.; Ko, Y. Sedation with dexmedetomidine prolongs the analgesic duration of brachial plexus block: A randomised controlled trial. Anaesth. Crit. Care Pain Med. 2019, 38, 231-236. [CrossRef] [PubMed]

12. Heesen, M.; Klimek, M.; Imberger, G.; Hoeks, S.E.; Rossaint, R.; Straube, S. Co-administration of dexamethasone with peripheral nerve block: Intravenous vs perineural application: Systematic review, meta-analysis, meta-regression and trial-sequential analysis. Br. J. Anaesth. 2018, 120, 212-227. [CrossRef]

13. Abdallah, F.W.; Dwyer, T.; Chan, V.W.; Niazi, A.U.; Ogilvie-Harris, D.J.; Oldfield, S.; Patel, R.; Oh, J.; Brull, R. IV and Perineural Dexmedetomidine Similarly Prolong the Duration of Analgesia after Interscalene Brachial Plexus Block: A Randomized, Threearm, Triple-masked, Placebo-controlled Trial. Anesthesiology 2016, 124, 683-695. [CrossRef] [PubMed]

14. Chong, M.A.; Berbenetz, N.M.; Lin, C.; Singh, S. Perineural Versus Intravenous Dexamethasone as an Adjuvant for Peripheral Nerve Blocks: A Systematic Review and Meta-Analysis. Reg. Anesth. Pain Med. 2017, 42, 319-326. [CrossRef]

15. Zhao, W.L.; Ou, X.F.; Liu, J.; Zhang, W.S. Perineural versus intravenous dexamethasone as an adjuvant in regional anesthesia: A systematic review and meta-analysis. J. Pain Res. 2017, 10, 1529-1543. [CrossRef]

16. Ahuja, V.; Thapa, D.; Chander, A.; Gombar, S.; Gupta, R.; Gupta, S. Role of dexmedetomidine as adjuvant in postoperative sciatic popliteal and adductor canal analgesia in trauma patients: A randomized controlled trial. Korean J. Pain 2020, 33, 166-175. [CrossRef]

17. Harris, P.A.; Taylor, R.; Minor, B.L.; Elliott, V.; Fernandez, M.; O’Neal, L.; McLeod, L.; Delacqua, G.; Delacqua, F.; Kirby, J.; et al. The REDCap consortium: Building an international community of software platform partners. J. Biomed. Inform. $2019,95,103208$. [CrossRef]

18. Schulz, K.F.; Altman, D.G.; Moher, D.; Group, C. CONSORT 2010 statement: Updated guidelines for reporting parallel group randomised trials. BMJ 2010, 340, c332. [CrossRef] 
19. Kang, R.; Jeong, J.S.; Yoo, J.C.; Lee, J.H.; Choi, S.J.; Gwak, M.S.; Hahm, T.S.; Huh, J.; Ko, J.S. Effective Dose of Intravenous Dexmedetomidine to Prolong the Analgesic Duration of Interscalene Brachial Plexus Block: A Single-Center, Prospective, Double-Blind, Randomized Controlled Trial. Reg. Anesth. Pain Med. 2018, 43, 488-495. [CrossRef]

20. Singapura, R.; Dalvani, K.; Jadeja, C.; Majhi, S.; Patel, J. A comparative study of effect of intravenous dexmedetomidine vs. placebo before brachial plexus block on patient satisfaction and success of block. Int. J. Pharm. Sci. Res. 2016, 7, 3486.

21. Kathuria, S.; Gupta, S.; Dhawan, I. Dexmedetomidine as an adjuvant to ropivacaine in supraclavicular brachial plexus block. Saudi J. Anaesth. 2015, 9, 148-154. [CrossRef] [PubMed]

22. Rodrigues, D.; Amadeo, R.J.J.; Wolfe, S.; Girling, L.; Funk, F.; Fidler, K.; Brown, H.; Leiter, J.; Old, J.; MacDonald, P.; et al. Analgesic duration of interscalene block after outpatient arthroscopic shoulder surgery with intravenous dexamethasone, intravenous dexmedetomidine, or their combination: A randomized-controlled trial. Can. J. Anaesth. 2021, 68, 835-845. [CrossRef]

23. Kang, R.A.; Jeong, J.S.; Yoo, J.C.; Lee, J.H.; Gwak, M.S.; Choi, S.J.; Hahm, T.S.; Cho, H.S.; Ko, J.S. Improvement in postoperative pain control by combined use of intravenous dexamethasone with intravenous dexmedetomidine after interscalene brachial plexus block for arthroscopic shoulder surgery: A randomised controlled trial. Eur. J. Anaesthesiol. 2019, 36, 360-368. [CrossRef]

24. Abdallah, F.W.; Johnson, J.; Chan, V.; Murgatroyd, H.; Ghafari, M.; Ami, N.; Jin, R.; Brull, R. Intravenous dexamethasone and perineural dexamethasone similarly prolong the duration of analgesia after supraclavicular brachial plexus block: A randomized, triple-arm, double-blind, placebo-controlled trial. Reg. Anesth. Pain Med. 2015, 40, 125-132. [CrossRef] [PubMed]

25. Sehmbi, H.; Brull, R.; Ceballos, K.R.; Shah, U.J.; Martin, J.; Tobias, A.; Solo, K.; Abdallah, F.W. Perineural and intravenous dexamethasone and dexmedetomidine: Network meta-analysis of adjunctive effects on supraclavicular brachial plexus block. Anaesthesia 2021, 76, 974-990. [CrossRef]

26. Desmet, M.; Braems, H.; Reynvoet, M.; Plasschaert, S.; Van Cauwelaert, J.; Pottel, H.; Carlier, S.; Missant, C.; Van de Velde, M.I.V. and perineural dexamethasone are equivalent in increasing the analgesic duration of a single-shot interscalene block with ropivacaine for shoulder surgery: A prospective, randomized, placebo-controlled study. Br. J. Anaesth. 2013, 111, 445-452. [CrossRef]

27. Teshome, D.; Fenta, E.; Hunie, M. Intravenous dexamethasone and peripheral nerve blocks: A systemic review and meta-analysis of randomized controlled trials. Int. J. Surg. Open 2020, 26, 86-96. [CrossRef]

28. Kim, B.-G.; Lee, W.; Song, J.H.; Yang, C.; Heo, G.A.; Kim, H. Effect of intravenous dexamethasone on the duration of postoperative analgesia for popliteal sciatic nerve block: A randomized, double-blind, placebo-controlled study. Korean J. Anesthesiol. 2021, 74, 317-324. [CrossRef] 